\title{
O estado da arte da Competência em Informação na educação profissional brasileira mediada pelo bibliotecário através da Educação a Distância (EAD)
}

\author{
The state of the art of Information Literacy in Brazilian vocational education mediated by
} library through Distance Education

\author{
Maurício dos Santos Júnior \\ Mestrando em Ciência da Informação \\ Universidade Federal de Sergipe \\ mauricio.santos.doc@hotmail.com \\ Pablo Boaventura Sales Paixão \\ Doutor em Ciência da Informação \\ Universidade Federal de Sergipe \\ pabloboaventura1@hotmail.com
}

\begin{abstract}
Resumo
Este artigo apresenta o resultado de pesquisa que verificou como a temática Competência em Informação na Educação Profissional e Tecnológica, mediada pelo bibliotecário por meio da Educação a Distância vem sendo discutida nos trabalhos científicos realizados no Brasil, por pesquisadores da Ciência da Informação na última década, que compreende os anos de 2008 a 2018. Como trajetória metodológica, empregou-se uma pesquisa qualitativa e exploratória, o que possibilitou a construção do estado da arte sobre o tema. As produções recuperadas foram analisadas qualitativamente, a fim de auxiliar interessados na temática para estruturar futuros estudos no campo da Ciência da Informação. As análises evidenciaram que o tema vem sendo pouco explorado pela comunidade acadêmica, sendo necessária a realização de pesquisas destinadas a articular as competências informacionais aos processos educacionais da Educação Profissional e Tecnológica.
\end{abstract}

\section{Palavras-chave}

Competência em Informação. Educação Profissional. Mediação da Aprendizagem. Educação a Distância.

\begin{abstract}
This article presents the result of research that verified how the theme of Information Literacy in Professional and Technological Education, mediated by the librarian through Distance Education, has been discussed in the scientific works carried out in Brazil, by researchers of Information Science in the last decade, which comprises the years 2008 to 2018. As a methodological trajectory, a qualitative and exploratory research was used, which enabled the construction of the state of the art on the subject. The recovered productions were analyzed qualitatively, in order to help those interested in the theme to structure future studies in the field of Information Science. The analyzes showed that the topic has been little explored by the academic community, making it necessary to carry out research aimed at articulating information competences to the educational processes of Professional and Technological Education.
\end{abstract}

\section{Keywords}

Information Literacy. Vocational Education. Learning mediation. Distance Education. 


\section{INTRODUÇÃO}

A contemporaneidade é marcada por rápidas mudanças e transformações sociais, decorrentes do acelerado trânsito e dos fluxos de informação, muito influenciados pelo avanço das Tecnologias da Informação e Comunicação (TICS). Esse contexto requer um novo olhar por parte dos profissionais de todas as áreas do conhecimento a respeito do seu fazer profissional (CASTELLS, 2011). Ao aproximar esse argumento para os profissionais da informação e, mais especificamente, para bibliotecários, é notável o papel que esses profissionais passam a exercer numa sociedade pós-industrial, onde a informação assume lugar de destaque na produção e na economia global.

Nessa perspectiva, os bibliotecários passam a desempenhar um papel de grande relevância no que compete à capacitação de usuários a respeito da identificação e avaliação de fontes de informação, bem como a conhecer critérios e ferramentas para a busca e uso dessas fontes. Para tanto, devem orientar os usuários das unidades de informação na utilização das TICS, e contribuir para o desenvolvimento de habilidades para que, estes, possam reconhecer as suas próprias necessidades informacionais, selecionar sistematicamente a informação e, para, enfim, poder organizá-las a fim de construir conhecimentos a partir de uma aprendizagem contínua. (SPUDEIT, 2015).

No âmbito da Educação Profissional e Tecnológica (EPT), o desenvolvimento de habilidades em Competência em Informação se torna fator decisivo no que compete à potencialização da empregabilidade dos estudantes dessa modalidade de ensino. Tais habilidades devem auxiliá-los a melhor interagir com as tecnologias informacionais, inserindo-os na cibercultura, contexto social e cultural que atualmente se desenvolve a partir do uso da rede de computadores e de outros suportes tecnológicos. Dessa forma, a Competência em Informação na Educação Profissional visa preparar o estudante para melhor inserção no mercado de trabalho, e, também, para o exercício da cidadania dentro do atual contexto da Sociedade da Informação.

Ao revisar a literatura em Biblioteconomia e Ciência da Informação, fica evidente o consenso dos pesquisadores sobre a necessidade de uma nova postura dos profissionais bibliotecários frente ao modo de produção contemporâneo, cunhada por Castells (2011) como o "Capitalismo Informacional". Esse argumento implica na necessidade de repensar a formação das pessoas no intuito de melhor prepará-las para os desafios da evolução tecnológica e as novas formas de produção, disseminação e consumo decorrentes dela (SOUSA, 2014).

Dessa forma, a contínua formação do bibliotecário se faz imprescindível para que possa se atualizar no tocante aos recursos informacionais digitais, a fim de melhor orientar os usuários das unidades de informação quanto ao uso correto desses recursos. Logo, é cada vez mais necessária a postura de um bibliotecário educador.

O fazer bibliotecário não deve se limitar apenas aos tradicionais serviços do processamento técnico, circulação de materiais, disseminação da informação, etc. O profissional necessita exercer a profissão a partir de uma visão pedagógica, enxergando o aluno de forma mais completa ao entender as suas dificuldades de aprendizagem, levando em consideração fatores sociais, para que, dessa forma, se consiga melhor compreender as necessidades informacionais de determinados grupos. (MARTINS, 2017).

Conforme nos conta Almeida (2015), a ideia da biblioteca como organização aprendente ainda é pouco explorada na literatura científica brasileira da área da Ciência da Infor- 
mação. Tal abordagem surge no início dos anos 2000, a partir do trabalho de "Dudziak (2001) ao discorrer sobre a Infortation Literacy, conceito este que em sua tradução para a língua portuguesa no Brasil compreendemos por Competência em Informação.". (ALMEIDA, 2015, p. 11).

Apoiando-se nessa abordagem, de uma biblioteca trabalhando a informação aliada ao conhecimento e exercendo um importante papel ao fomentar o processo de mediação da aprendizagem, nota-se o potencial em termos de vantagem competitiva para as instituições de ensino. Quando a biblioteca desenvolve as habilidades de Competência em Informação nos seus usuários passa a ser mais um agente da Educação, a fim e desenvolver a aprendizagem nos ambientes educacionais.

A Competência em Informação pode ser considerada como um processo que corresponde às etapas de localizar, selecionar, acessar, organizar e usar a informação para fins de gerar conhecimento, com o intuito de facilitar a tomada de decisão e a resolução de problemas de informação (GASQUE, 2010).

No âmbito da EPT, é fundamental desenvolver, nos estudantes, as habilidades necessárias ao incremento da empregabilidade e inclusão social. Dessa forma, busca-se aumentar as chances de inserção no mundo do trabalho, frente às necessidades da atual Sociedade da Informação, marcada pelas dinâmicas do mercado financeiro e pelas inovações científicotecnológicas provenientes do fenômeno da globalização (SANTOS, 2017).

Nesse cenário, a Educação a Distância (EAD) surge como um facilitador no processo de mediação da informação e da aprendizagem por meio da qual a biblioteca pode ampliar exponencialmente os seus serviços. Torna-se uma opção de inclusão social flexível, na qual o usuário pode se capacitar sem necessariamente estar preso a um local ou a um determinado horário. Isso pode auxiliar os estudantes que vivem afastados das instituições de ensino, ou os que não dispõem de tempo para cursos presenciais de capacitação (MATTOS FILHA; ClANCONI, 2010).

Após essa breve explanação acerca do tema e da sua relevância, é cabível o questionamento: como estão sendo desenvolvidas as pesquisas a nível nacional em se tratando da Competência em Informação na EPT, e do bibliotecário como mediador da aprendizagem no contexto da EAD?

O presente artigo buscou verificar como as temáticas da Competência em Informação na EPT e da mediação da aprendizagem realizada pelo bibliotecário no contexto da EAD vêm sendo discutidas nos trabalhos científicos realizados no Brasil. Os resultados servirão para subsidiar o desenvolvimento de projeto de intervenção de uma pesquisa de mestrado profissional junto ao Programa de Pós-Graduação em Gestão da Informação e do Conhecimento da Universidade Federal de Sergipe (UFS). O referido projeto terá como produto um curso introdutório na modalidade EAD para o desenvolvimento de competências em informação de estudantes da EPT do Instituto Federal de Sergipe (IFS).

\section{PROCEDIMENTOS METODOLÓGICOS}

Do ponto de vista dos procedimentos metodológicos utilizados na elaboração deste artigo, empregou-se uma pesquisa qualitativa e exploratória, realizada por meio da revisão bibliográfica. A pesquisa qualitativa é definida por Dalfovo, Lana e Silveira $(2008$, p. 9) como "[...] aquela que trabalha predominantemente com dados qualitativos, isto é, a informação coletada pelo pesquisador não é expressa em números, ou então os números e as conclusões neles baseadas representam um papel menor na análise.". 
Seu caráter exploratório constitui-se da condição de aproximar e oferecer uma visão geral sobre determinado assunto (GIL, 1999). A revisão bibliográfica, por sua vez, possui o objetivo de buscar o "[...] estado da arte sobre determinado tema." (CERVO; BERVIAN, 2007, p. 61). Quanto ao significado de "estado da arte", Paixão (2017, p. 24) nos conta que:

[...] visa cartografar a produção acadêmica em um determinado campo do conhecimento, por meio da análise de dissertações, teses, publicações em periódicos, anais de congressos etc. O objetivo dessas pesquisas, de caráter bibliográfico, é buscar diferentes aspectos e dimensões atribuídas em diferentes épocas e locais.

Esse tipo de pesquisa possui em seu cerne um aspecto exploratório caracterizado pela revisão bibliográfica no intuito de discutir e mapear certas produções acadêmicas, além de proporcionar a aproximação e oferecer uma visão geral de determinado assunto.

Para conhecer e mapear as investigações das pesquisas no âmbito Ciência da Informação acerca da temática da Competência em Informação no que compete ao ensino profissionalizante no Brasil, mais especificamente no contexto da EAD, foi realizada pesquisa bibliográfica no Catálogo de Teses e Dissertações da Coordenação de Aperfeiçoamento de Pessoal do Nível Superior (CAPES), na Scientific Electronic Library Online (SciELO) e na Base de dados em Ciência da Informação (BRAPCl), tendo como marco temporal o período de 2008 a 2018.

Figura 1 - Diagrama conceitual dos procedimentos metodológicos

Levantamento bibliográfico a nível nacional em fontes bibliográficas secundárias (bases de dados textuais COMO BRAPCI, SCIELO e BDTD/CAPES).

\begin{tabular}{|c|}
\hline $\begin{array}{l}\text { Definição de palavras-chave para subsidiar o desenvol- } \\
\text { vimento da pesquisa bibliográfica feitas nas fontes de } \\
\text { bases de dados textuais já citadas. Os temas aborda- } \\
\text { dos foram: Competência em Informação, Letramento } \\
\text { Informacional, Alfabetização Informacional, Informa- } \\
\text { tion Literacy, Educação Profissional, EAD. Essas expres- } \\
\text { sões foram utilizadas por serem as mais recorrentes na } \\
\text { literatura sobre a temática deste trabalho. }\end{array}$ \\
\hline $\begin{array}{l}\text { Seleção de documentos a partir de critérios de perti- } \\
\text { nência com relação aos assuntos principais da pesqui- } \\
\text { sa, no idioma português, publicado entre } 2008 \text { e } 2018 \text {. }\end{array}$ \\
\hline $\begin{array}{l}\text { Leituras e fichamentos dos textos selecionados, que } \\
\text { possibilitaram a identificação e análise dos textos em } \\
\text { busca de um quadro teórico de referência para com- } \\
\text { por o Estado da Arte da Competência em Informação } \\
\text { em EPT e sobre a Mediação da Aprendizagem feita por } \\
\text { bibliotecários no contexto da EAD. }\end{array}$ \\
\hline
\end{tabular}

Fonte: elaborado pelos autores (2020). 
Como estratégia de busca utilizada nas fontes de informação foram delineadas as seguintes palavras-chave: competência em informação, alfabetização informacional, competência informacional, letramento informacional, information literacy, educação profissional, ensino profissionalizante e Educação a Distância (EAD). Esses termos foram combinados utilizando-se os operadores lógicos booleanos, and, or e and not com o objetivo de refinar a busca. Devido à natureza transdisciplinar do objeto de estudo, foram selecionados trabalhos acadêmicos não apenas da Ciência da Informação, mas também da Educação.

A Figura 1 apresenta um diagrama conceitual que sintetiza os procedimentos metodológicos empregados na investigação em tela.

O passo a passo demonstrado no diagrama conceitual exposto na Figura 1, foi de grande auxílio para a construção de um roteiro inicial com o intuito de servir como norte no desenvolvimento deste artigo, ajudando, por exemplo, na otimização de tempo gasto na pesquisa em bases de dados e na construção do texto, bem como numa maior familiaridade e compreensão do método científico.

\section{RESULTADOS DA PESQUISA}

O levantamento bibliográfico realizado nas fontes relacionadas no Quadro 1 teve como resultado um total de 78 trabalhos acadêmicos, distribuídos entre teses, dissertações e artigos científicos, além de relatos de pesquisas, comunicação oral e revisão de literatura, os quais estão descritos como "outros". O quadro está organizado de forma a trazer a quantidade de documentos recuperados em cada uma das três fontes, conforme a estratégia de busca utilizada.

Quadro 1 - Estratégias de busca e resultados

\begin{tabular}{|c|c|c|c|}
\hline Estratégia & Fonte & Tipo & Resultado \\
\hline \multirow{5}{*}{$\begin{array}{l}\text { Competência em informação OR In- } \\
\text { formation Literacy OR Letramento } \\
\text { informacional OR Alfabetização in- } \\
\text { formacional AND Educação profissio- } \\
\text { nal AND Educação a Distância }\end{array}$} & \multirow{2}{*}{$\begin{array}{l}\text { Teses e disserta- } \\
\text { ções da CAPES }\end{array}$} & Dissertações & 36 \\
\hline & & Teses & 10 \\
\hline & \multirow{2}{*}{$\mathrm{BRAPCl}$} & Artigo Científico & 10 \\
\hline & & Outros & 9 \\
\hline & SciELO & Artigo Científico & 13 \\
\hline
\end{tabular}

Fonte: Dados da pesquisa (2020).

A análise desses documentos demonstrou que as pesquisas referentes às necessidades informacionais de alunos da educação profissional ainda se encontram em estado germinativo. Embora tenham sido recuperados alguns trabalhos evidenciando análises das competências em informação necessárias a estudantes do ensino superior, pós-graduação e educação básica, apenas sete trabalhos foram recuperados com a especificidade do ensino profissionalizante.

As teses e dissertações indicadas no Quadro 2 oferecem modelos de desenvolvimento de práticas referentes à Competência em Informação no âmbito da Educação Profissional, provenientes dos estudos teóricos e experiências profissionais dos autores, a exemplo da tese de Santos (2017), onde é feita a inter-relação entre as "Sete Faces da Competência em Informação" e os "Padrões e indicadores de Competência em Informação", com as devidas adaptações às características da EPT. A tese foi desenvolvida tendo em vista a Escola Técnica 
de Marília, São Paulo, e voltada à competência em informação de alunos matriculados no III Módulo dos cursos de Educação Profissional do Campus.

Quadro 2 - Dissertações, teses e artigos científicos sobre Competência em Informação na Educação Profissional e Tecnológica

\begin{tabular}{|c|c|c|c|c|c|}
\hline Autoria & Ano & Título & Tipo & Programa & Revista \\
\hline ALMEIDA, J. L. S. A. & 2015 & $\begin{array}{l}\text { A biblioteca como } \\
\text { organização } \\
\text { aprendente: o } \\
\text { desenvolvimento de } \\
\text { competência em } \\
\text { informação no } \\
\text { Instituto Federal de } \\
\text { Educação, Ciência e } \\
\text { Tecnologia da Paraíba }\end{array}$ & Dissertação & $\begin{array}{l}\text { Pós-graduação em } \\
\text { Ciência, Tecnologia e } \\
\text { Sociedade, do Centro } \\
\text { de Educação e Ciências } \\
\text { Humanas, da } \\
\text { Universidade Federal de } \\
\text { São Carlos }\end{array}$ & - \\
\hline $\begin{array}{l}\text { ALMEIDA, J. L. S.; } \\
\text { FREIRE, G. H. A. }\end{array}$ & 2018 & $\begin{array}{l}\text { A biblioteca Multinível } \\
\text { no IFPB Campus Sousa: } \\
\text { conceito, descrição e } \\
\text { finalidade }\end{array}$ & Artigo Científico & - & $\begin{array}{l}\text { Informação } \\
\text { \& } \\
\text { Informação }\end{array}$ \\
\hline ANDRADE, L. R. S. & 2018 & $\begin{array}{l}\text { Alfabetização } \\
\text { informacional na } \\
\text { aprendizagem técnica } \\
\text { profissionalizante: } \\
\text { uma pesquisa do tipo } \\
\text { ação/intervenção }\end{array}$ & Dissertação & $\begin{array}{l}\text { Programa de Pós- } \\
\text { graduação em Educação } \\
\text { na linha Educação e } \\
\text { Comunicação - } \\
\text { Universidade } \\
\text { Tiradentes. }\end{array}$ & - \\
\hline DUPIN, A. A. S. Q. & 2018 & $\begin{array}{l}\text { Competência em } \\
\text { informação para } \\
\text { pesquisa científica de } \\
\text { estudantes de cursos } \\
\text { tecnológicos do } \\
\text { Instituto Federal de } \\
\text { Educação, Ciência e } \\
\text { Tecnologia de São } \\
\text { Paulo - IFSP }\end{array}$ & Dissertação & $\begin{array}{l}\text { Pós-graduação em } \\
\text { Ciência, Tecnologia e } \\
\text { Sociedade, do Centro } \\
\text { de Educação e Ciências } \\
\text { Humanas, da } \\
\text { Universidade Federal de } \\
\text { São Carlos }\end{array}$ & - \\
\hline SANTOS, C. A. S. & 2017 & $\begin{array}{l}\text { Competência em } \\
\text { Informação na } \\
\text { formação básica dos } \\
\text { estudantes da } \\
\text { Educação Profissional } \\
\text { e Tecnológica }\end{array}$ & Tese & $\begin{array}{l}\text { Programa de Pós- } \\
\text { Graduação em Ciência } \\
\text { da Informação da } \\
\text { Faculdade de Filosofia e } \\
\text { Ciências da } \\
\text { Universidade Estadual } \\
\text { Paulista (UNESP) }\end{array}$ & - \\
\hline SPUDEIT. D. & 2015 & $\begin{array}{l}\text { Proposta de um } \\
\text { programa para } \\
\text { desenvolvimento de } \\
\text { competência em } \\
\text { informação para } \\
\text { alunos do ensino } \\
\text { profissional }\end{array}$ & Artigo Científico & - & $\begin{array}{l}\text { Ciência da } \\
\text { Informação } \\
\text { em revista }\end{array}$ \\
\hline VEIGAR, M. S. & 2017 & $\begin{array}{l}\text { Prática de letramento } \\
\text { informacional: o uso } \\
\text { da informação como } \\
\text { caminho da } \\
\text { aprendizagem nas } \\
\text { bibliotecas multiníveis } \\
\text { do Instituto Federal de } \\
\text { Rondônia }\end{array}$ & Dissertação & $\begin{array}{l}\text { Programa de Pós- } \\
\text { Graduação em } \\
\text { Educação Escolar - } \\
\text { Mestrado Profissional } \\
\text { da Universidade Federal } \\
\text { de Rondônia (UNIR) }\end{array}$ & - \\
\hline
\end{tabular}

Fonte: Dados da pesquisa (2020). 
Com a proposta de utilizar como referência as sete faces da Competência em Informação de Santos (2017), elencamos sete padrões no Quadro 3.

\section{Quadro 3 - Padrões de Competência em Informação na ETP}

\begin{tabular}{|c|c|c|}
\hline Ordem & Padrões & Descrição \\
\hline 1 운 & Experiência em tecnologia da informação & $\begin{array}{l}\text { Onde os alunos devem saber usar os softwares } \\
\text { básicos. }\end{array}$ \\
\hline 20 & Experiência em processos de informação & $\begin{array}{l}\text { Onde os alunos devem ser capazes de identificar } \\
\text { fontes de informação. }\end{array}$ \\
\hline 3은 & Experiência em processo de informação & $\begin{array}{l}\text { Onde os alunos devem ser capazes de articular o } \\
\text { conhecimento científico e o tecnológico. }\end{array}$ \\
\hline 40 & Experiência em controle informacional & $\begin{array}{l}\text { Onde o aluno deve ser capaz de definir e executar } \\
\text { cronogramas de trabalho. }\end{array}$ \\
\hline 5은 & Experiência da construção do conhecimento & $\begin{array}{l}\text { Onde o aluno deve saber reunir e classificar infor- } \\
\text { mações de acordo com seus objetivos de trabalho. }\end{array}$ \\
\hline 6은 & Experiência da extensão do conhecimento & $\begin{array}{l}\text { Onde o aluno deve saber sintetizar a informação } \\
\text { recuperada. }\end{array}$ \\
\hline 70 & Experiência da sabedoria & $\begin{array}{l}\text { Onde o aluno deve saber utilizar e comunicar a } \\
\text { informação para intervir na sua realidade. }\end{array}$ \\
\hline
\end{tabular}

Fonte: Dados da pesquisa (2020).

Já em Dupin (2018), o objetivo é investigar como se estabelece a pesquisa acadêmica no que concerne à Competência em Informação de estudantes de cursos de Tecnologias do Instituto Federal de Educação, Ciência e Tecnologia de São Paulo (IFSP). A estratégia adotada pela autora consistiu na seleção e análise de monografias disponíveis para acesso público da internet dos campi do IFSP, resultando em uma amostra de 96 trabalhos de conclusão de curso.

Além desses trabalhos, foram analisadas também as Matrizes Curriculares e os Projetos Políticos Pedagógicos dos cursos ofertados no IFSP, bem como as páginas na Internet das bibliotecas dos campi, em que se buscou identificar os recursos informacionais disponibilizados pelas unidades aos seus usuários, verificando a existência ou não de treinamentos e orientações em relação à construção da pesquisa científica.

Em Almeida (2015), é discutida a ideia de biblioteca como organização aprendente, que exerce o papel educacional de desenvolver as competências em informação dos seus usuários. Também como essa tarefa se faz desafiadora no contexto das bibliotecas dos Institutos Federais de Educação (IFEs), chamadas pelo autor de bibliotecas multiníveis, por serem tão diversificadas em suas modalidades, tendo características de biblioteca escolar, pública, universitária e especializada.

O autor propõe um projeto educativo com o objetivo de contribuir para o desenvolvimento de competências em informação dos usuários da biblioteca do Instituto Federal da Paraíba (IFPB), Campus Sousa, a servir de referência para bibliotecários educadores nas bibliotecas multiníveis dos IFEs. Esse projeto educativo é composto por um roteiro de atividades a serem desenvolvidas na biblioteca que estão divididas em quatro eixos, são eles: eixo profissional, com quatro ações, eixo científico, com 19 ações, eixo tecnológico, com três ações, e o eixo cultural, com seis ações.

Em Veiga (2017), o termo adotado em substituição a Competência em Informação é Letramento Informacional. O objetivo da sua dissertação foi entender as práticas de Letramento Informacional e o uso da informação pelas bibliotecas multiníveis do Instituto Federal 
de Educação, Ciência e Tecnologia de Rondônia (IFRO), segundo a ação dos profissionais bibliotecários, com foco no perfil informacional de alunos e professores.

Para tal, a autora construiu um Programa Educativo de Letramento Informacional tendo com base na proposta de conteúdos de Letramento Informacional para o Ensino Médio, criado por Gasque (2011), e o projeto educativo em Competências Informacionais criado por Almeida (2015), bem como os conceitos de biblioteca aprendente e multinível que foram trabalhados ainda em Almeida (2015).

Por último, na dissertação de Andrade (2018), encontramos o termo Alfabetização Informacional, e o objetivo da sua pesquisa foi investigar as possiblidades e as formas do uso de oficina como estratégia pedagógica para o desenvolvimento, por parte de jovens estudantes, da Competência em Informação.

A amostra da pesquisa foi composta por estudantes do Ensino Técnico Profissionalizante da Escola Família Agrícola de Ladeirinhas (EFAL), localizada na região do baixo São Francisco sergipano. A oficina teve como principal norte as diretrizes da Organização das Nações Unidas para a Educação, a Ciência e a Cultura (UNESCO) para o desenvolvimento de competências informacionais, são elas: 1) definir e articular necessidades informacionais, 2) localizar e acessar a informação, 3) acessar a informação, 4) organizar a informação, 5) usar eticamente a informação, 6) comunicar a informação, e 7) usar das habilidades de TICs no processamento de informação.

Ao final da análise desses cinco trabalhos, foram definidos como principais nortes para a futura dissertação, pela qual se propõe subsidiar este presente estado da arte, os trabaIhos de Almeida (2015) e Santos (2017), pois contemplam projetos educacionais mais robustos e consistentes para o desenvolvimento da Competência em Informação na EPT.

Além das dissertações e teses apresentadas, foram recuperados apenas dois artigos científicos com a temática da Competência em Informação na ETP, o que vem reforçar o quanto o tema é pouco explorado no contexto nacional. O trabalho de Spudeit (2015) apresenta um programa para o desenvolvimento de Competência em Informação para alunos da Educação Profissional. A primeira pesquisa consiste num estudo de caso desenvolvido na biblioteca do Serviço Nacional de Aprendizagem Comercial (SESC) de Florianópolis, onde foram estruturadas ações para desenvolver a Competência em Informação e transformadas em um programa voltado para as necessidades informacionais dos estudantes dessa instituição.

O trabalho aborda temas como a discussão sobre a formação dos licenciados e bacharéis em Biblioteconomia para elaboração de programas de desenvolvimento de Competência em Informação, além de trazer alguns exemplos de programas existentes e de destacar as diretrizes internacionais que devem gerir tais programas. 0 estudo também apresenta indicadores de avaliação para medir a eficácia desses programas.

O trabalho de Almeida e Freire (2018) é de grande importância para a compreensão do tipo de biblioteca da Rede Federal de Educação Profissional, Científica e Tecnológica do Brasil, considerada pelos autores como um novo tipo de biblioteca, a biblioteca multinível, assim definida por atender aos usuários de múltiplos níveis de ensino. Portanto, os autores buscaram definir e expor a finalidade da biblioteca multinível.

No tocante ao desenvolvimento de Competência em Informação através da EAD, tendo o bibliotecário como mediador, foram recuperados, apenas três trabalhos para compor o referencial teórico sobre essa temática, conforme Quadro 4 
Quadro 4 - Trabalhos sobre a Educação a Distância mediada por Bibliotecários

\begin{tabular}{|l|l|l|l|}
\hline \multicolumn{1}{|c|}{ Autoria } & Ano & \multicolumn{1}{|c|}{ Título } & \multicolumn{1}{|c|}{ Tipo } \\
\hline $\begin{array}{l}\text { MATTOS FILHA, M. H. F.; } \\
\text { CIANCONI, R. B. }\end{array}$ & 2010 & $\begin{array}{l}\text { Bibliotecário e Educação a Distância (EAD): } \\
\text { mediando os instrumentos do } \\
\text { conhecimento }\end{array}$ & Artigo Científico \\
\hline $\begin{array}{l}\text { SPUDEIT, D. F. A. O.; VIAPIANA, } \\
\text { N.; VITORINO, E. V. }\end{array}$ & 2010 & $\begin{array}{l}\text { Bibliotecário e Educação a Distância (EAD): } \\
\text { mediando os instrumentos do } \\
\text { conhecimento }\end{array}$ & Artigo Científico \\
\hline VITORINO, E. V. & 2009 & $\begin{array}{l}\text { A perspectiva da competência } \\
\text { informacional na Educação a Distância } \\
\text { (EAD) }\end{array}$ & Artigo Científico \\
\hline
\end{tabular}

Fonte: Dados da pesquisa (2020).

Analisando os trabalhos dispostos no Quadro 5, começando pela pesquisa de Spudeit, Viaiana e Vitorino (2010), destaca-se a necessidade de formação de equipes interdisciplinares com a participação do bibliotecário na construção de um espaço virtual de aprendizagem voltado para a EAD. Para o sucesso de um projeto de curso a distância, é fundamental que o bibliotecário atue como mediador da informação, no ambiente de aprendizagem virtual, contribuindo para a construção do conhecimento e o desenvolvimento da Competência em Informação dos alunos e da equipe pedagógica como um todo.

Em Mattos Filha e Cianconi (2010), foi realizada uma pesquisa com alunos de três cursos a distância no polo de ensino do Centro de Educação Superior a Distância do Estado do Rio de Janeiro (CEDERJ). Nessa pesquisa foram coletados, por meio de questionários, dados sobre os hábitos de busca e uso da informação por parte dos estudantes. A pesquisa buscou analisar o papel desempenhado e os serviços oferecidos pelas bibliotecas na EAD, bem como as necessidades informacionais dos estudantes.

Por fim, Vitorino (2009) discorre sobre a ideia de aprendizagem contínua, principalmente, no contexto de flexibilidade da EAD. Além disso, sobre a alfabetização digital e a construção de conhecimento, atrelada a pretensão de desenvolver a Competência em Informação na EAD. Para a autora, o desenvolvimento da Competência em Informação é fundamental para o âmbito da EAD, pois a relação pedagógica que se estabelece nessa modalidade de ensino está impregnada por uma cultural digital onde imperam as TICs.

Por fim, dentre os resultados obtidos através da estratégia de busca da pesquisa bibliográfica, foram selecionados alguns trabalhos que, mesmo não tendo relação com a temática da Educação Profissional e nem com a EAD, são relevantes para a pesquisa no que compete à caracterização da Competência em Informação e o papel educativo do bibliotecário. Dessa forma os trabalhos listados no Quadro 5 serão utilizados para caracterizar os conceitos de Competência em Informação, e o entendimento do bibliotecário como um agente da Educação.

A análise dos trabalhos relacionados no quadro 6 evidenciou o papel educativo atribuído ao bibliotecário como sendo inerente ao processo de mediação da informação por meio do qual desenvolve habilidades em Competência em Informação nos usuários da biblioteca. Sendo, - conforme os autores analisados no quadro 6 - a Competência em Informação, um conjunto de habilidades pelo qual o indivíduo necessita ter o domínio para lidar, de forma crítica e reflexiva com a informação, é notável a sua importância quanto ao o processo de ensino-aprendizagem. Ao reconhecer suas necessidades informacionais, apropriar-se da informação e construir conhecimento, o indivíduo alcança a autonomia informacional por 
meio da aprendizagem permanente, cumprindo com os preceitos de uma educação emancipatória.

Quadro 5 - Trabalhos Acadêmicos para o auxílio da caraterização da Competência em Informação e o bibliotecário como agente da Educação

\begin{tabular}{|c|c|c|c|}
\hline Autoria & Ano & Título & Formato \\
\hline $\begin{array}{l}\text { FARIAS, C. M.; } \\
\text { VITORINO, E. V. }\end{array}$ & 2009 & $\begin{array}{l}\text { Competência Informacional e dimensões da } \\
\text { competência do bibliotecário no contexto } \\
\text { escolar }\end{array}$ & Artigo Científico \\
\hline GASQUE, K. C. G. D. & 2011 & $\begin{array}{l}\text { Pesquisas na pós-graduação: o uso do } \\
\text { pensamento reflexivo no letramento } \\
\text { informacional }\end{array}$ & Artigo Científico \\
\hline GASQUE, K. C. G. D. & 2010 & $\begin{array}{l}\text { Arcabouço conceitual do letramento } \\
\text { informacional }\end{array}$ & Artigo Científico \\
\hline NASCIMENTO, L. S. & 2018 & $\begin{array}{l}\text { Informação e Educação: as origens da } \\
\text { Information Literacy - um estudo sobre o } \\
\text { relatório "The Information Service Evironment } \\
\text { Relationships and Priorities" de Paul Zurkowski }\end{array}$ & Dissertação \\
\hline $\begin{array}{l}\text { ORELO, E. R. M.; } \\
\text { VITORINO, E. V. }\end{array}$ & 2012 & $\begin{array}{l}\text { Competência informacional: um olhar para a } \\
\text { dimensão estética }\end{array}$ & Artigo Científico \\
\hline PASSOS, M. P. & 2018 & $\begin{array}{l}\text { Informação e Educação: um estudo sobre as } \\
\text { relações entre atitudes, saberes e dispositivos } \\
\text { culturais }\end{array}$ & Tese \\
\hline PELLEGRINE, E. & 2016 & $\begin{array}{l}\text { A dimensão Ética da Competência em } \\
\text { Informação: a experiência narrada dos } \\
\text { bibliotecários do Instituto Federal de } \\
\text { Educação, Ciência e Tecnologia de Santa } \\
\text { Catarina (IFSC) }\end{array}$ & Dissertação \\
\hline SOUSA, M. M. & 2014 & $\begin{array}{l}\text { A função educativa do Bibliotecário no século } \\
\text { XXI: desafios para sua formação e atuação }\end{array}$ & Tese \\
\hline $\begin{array}{l}\text { VITORINO, E. V.; } \\
\text { PIANTOLA, D. }\end{array}$ & 2011 & Dimensões da competência informacional & Artigo Científico \\
\hline $\begin{array}{l}\text { VITORINO, E. V.; } \\
\text { PIANTOLA, D. }\end{array}$ & 2009 & $\begin{array}{l}\text { Competência informacional - bases históricas } \\
\text { e conceituais: construindo significados }\end{array}$ & Artigo Científico \\
\hline
\end{tabular}

Fonte: Dados da pesquisa (2020).

Nesse contexto, o bibliotecário exerce o seu papel de educador ao contribuir para a formação de indivíduos competentes em informação, dotados de autonomia de aprendizagem e socialmente empoderados.

\section{CONSIDERAÇÕES FINAIS}

Após a leitura de todos os textos selecionados em quadros ao longo da seção anterior, fica evidente a grande lacuna no período de tempo que vai de 2008 a 2014, uma vez que, nesse período, nenhum trabalho com a temática da Competência em informação na educação profissional foi recuperado. Apenas, a partir de 2015, houve resultados na busca, com dois trabalhos recuperados neste mesmo ano, já em 2016 não houve resultados.

Em 2017, foram recuperados mais dois trabalhos e a maior concentração dos resultados encontra-se no ano de 2018, ano em que foram recuperados mais três. Quanto ao bibliotecário na EAD, foram recuperados apenas três trabalhos correspondentes aos anos de 
2009 e 2010, o que demonstra uma pausa de oito anos sem nenhuma pesquisa sobre a temática.

Portanto, a análise qualitativa feita nos textos selecionados no período de 2008 a 2018 demonstra que, em se tratando da Competência em Informação na Educação Profissional, Cientifica e Tecnológica, as pesquisas sobre o tema ainda se encontram em estado incipiente. Com resultados obtidos apenas a partir do ano de 2015 , percebe-se um campo ainda muito pouco explorado pela literatura. Tal observação confirma a relevância do presente artigo, que buscou mapear, a nível nacional, as pesquisas feitas sobre essa temática no intuito de criar um referencial teórico capaz de subsidiar futuras pesquisas.

Percebeu-se, também, uma baixa produção acerca do profissional bibliotecário como mediador da aprendizagem na EAD, sendo recuperados apenas três artigos científicos correspondentes aos anos de 2009 e 2010, o que revela uma lacuna de oito anos sem nenhuma pesquisa realizada neste tema.

Nesse sentido, uma pesquisa no âmbito da atuação do bibliotecário desenvolvendo a Competência em Informação na Educação Profissional, Científica e Tecnológica, por meio da $E A D$, pode ser considerada promissora e, de certa forma, inovadora, tendo em vista que o tema é ainda muito pouco explorado na Ciência da Informação, como pôde ser demonstrado na análise do estado da arte. Os objetivos aqui propostos foram alcançados de forma satisfatória, ao passo que os resultados desta pesquisa poderão servir de auxílio para futuros trabalhos. Esta pode contribuir com os estudos na área da Ciência da Informação, mais precisamente na estratégia de gestão das bibliotecas que pretendem utilizar-se da Competência em Informação para incrementar as vantagens competitivas das instituições de ensino a que pertencem.

\section{REFERÊNCIAS}

ALMEIDA, J. L. S. A biblioteca como organização aprendente: o desenvolvimento de competência em informação no Instituto Federal de Educação, Ciência e Tecnologia da Paraíba. 2015. 123f. Dissertação (Mestrado em Gestão nas Organizações Aprendentes) - Universidade Federal da Paraíba, João Pessoa, 2015. Disponível em: https://repositorio.ufpb.br/jspui/bitstream/tede/7671/2/arquivototal.pdf. Acesso em: 27 jun. 2020.

ALMEIDA, J. L. S.; FREIRE, G. H. A. A biblioteca Multinível do IFPB Campus Sousa: conceito, descrição e finalidade. Informação \& Informação, Londrina, v. 23, n. 2, p. 520-537, maio/ago. 2018. Disponível em: https://brapci.inf.br/index.php/res/download/46287. Acesso em: 27 jun. 2020.

ANDRADE, L. R. S. Alfabetização Informacional na aprendizagem técnica profissionalizante: uma pesquisa do tipo ação/intervenção. 2018. 124 p. Dissertação (Mestre em Educação) Universidade Tiradentes, Aracaju, 2018. Disponível em:

https://openrit.grupotiradentes.com/xmlui/bitstream/handle/set/2539/ALFABETIZA\%c3\%87 \%c3\%830-INFORMACIONAL-NA-APRENDIZAGEM-T\%c3\%89CNICA.pdf?sequence=1. Acesso em: 27 jun. 2020.

CASTELLS, M. A sociedade em rede. 6. ed. São Paulo: Paz e Terra, 2011. 698p. v. 1. 
CERVO, A. L.; BERVIAN, P. A. Metodologia científica. 6. ed. São Paulo: Prentice Hall, 2007.

DALFOVO, M. S.; LANA, R. A.; SILVEIRA, A. Métodos quantitativos e qualitativos: um resgate teórico. Revista Interdisciplinar Científica Aplicada, Blumenau, v. 2, n. 3, p. 1- 13, 2. sem. 2008.

DUPIN, A. A. S. Q. Competência em Informação para pesquisa científica em cursos tecnológicos do Instituto Federal de Educação, Ciência e Tecnologia de São Paulo IFSP. 2018. 127 p. Dissertação (Mestre em Ciência, tecnologia e sociedade) - Universidade Federal de São Carlos, São Carlos, 2018. Disponível em:

https://repositorio.ufscar.br/bitstream/handle/ufscar/9540/DUPIN Aline 2018.pdf?sequen ce=4\&isAllowed=y. Acesso em: 27 jun. 2020.

FARIAS, C. M.; VITORINO, E. V. Competência informacional e dimensões da competência do bibliotecário no contexto escolar. Perspectivas em Ciência da Informação, Belo Horizonte, v. 14, n. 2, p. 2-16, maio/ago. 2009. Disponível em:

http://portaldeperiodicos.eci.ufmg.br/index.php/pci/article/view/699/575. Acesso em: 27 jun. 2020.

GASQUE, K. C. G. D. Arcabouço conceitual do letramento informacional. Ciência da Informação, Brasília, v. 39, n. 3, p. 83-92, set./dez. 2010. Disponível em:

http://revista.ibict.br/ciinf/article/view/1268/1446. Acesso em: 27 jun. 2020.

GASQUE, K. C. G. Pesquisas na pós-graduação: o uso do pensamento reflexivo no letramento informacional. Ciência da Informação, Brasília, v. 40, n. 1, p. 22-37, jan./abr. 2011. Disponível em: http://revista.ibict.br/ciinf/article/view/1322/1501. Acesso em: 27 jun. 2020.

GIL, A. C. Métodos e técnicas de pesquisa social. 7. ed. São Paulo: Atlas, 2019.

MARTINS, L. G. Bibliotecário como mediador da aprendizagem: uma proposta a partir do uso das TICs. Biblos, Rio Grande do Sul, v. 31, n. 2, p. 73-98, jun. /dez. 2017. Disponível em: https://periodicos.furg.br/biblos/article/view/5602/5269. Acesso em: 27 jun. 2020.

MATTOS FILHA, M. H. F.; CIANCONI, R. B. Bibliotecas na Educação a Distância: caso do consórcio CEDERJ. Informação \& Sociedade: estudos, João Pessoa, v. 20, n. 1, p. 129-138, jan. /abr. 2010. Disponível em: https://periodicos.ufpb.br/ojs2/index.php/ies/article/view/4037/3425. Acesso em: 27 jun. 2020.

NASCIMENTO, L. S. Informação e Educação: as origens da Information Literacy - um estudo sobre o relatório "The Information Service Evironment Relationships and Priorities" de Paul Zurkowski. 2018. 152 p. Dissertação (Mestre em Ciência da Informação) - Escola de Comunicação e Artes da Universidade de São Paulo, São Paulo, 2018. Disponível em: https://www.teses.usp.br/teses/disponiveis/27/27151/tde-03122018153225/publico/LeandrodosSantosNascimento.pdf. Acesso em: 27 jun. 2020. 
ORELO, E. R. M.; VITORINO, E. V. Competência informacional: um olhar para a dimensão estética. Perspectivas em Ciência da Informação, Belo Horizonte, v. 17, n. 4, p. 41-56, out./dez. 2012. Disponível em:

http://portaldeperiodicos.eci.ufmg.br/index.php/pci/article/view/1614/1066. Acesso em: 27 jun. 2020.

PAIXÃO, P. B. S. As Competências Informacionais na Educação a Distância na Universidade: estudo de caso Universidade Tiradentes. 2017. 404 p. Tese (Doutorado em Ciência da Informação) - Universidad Complutense de Madrid, Madrid, 2016. Disponível em: https://eprints.ucm.es/44225/1/T39074.pdf. Acesso em: 26 jul. 2020.

PASSOS, M. P. Informação e Educação: um estudo sobre as relações entre atitudes, saberes e dispositivos culturais. 2018. 206 p. Tese (Doutorado em Ciência da Informação) - Escola de Comunicação e Artes da Universidade de São Paulo, São Paulo, 2018. Disponível em: https://www.teses.usp.br/teses/disponiveis/27/27151/tde-11092018094658/publico/MARCOSPAULODEPASSOS.pdf. Acesso em: 26 jul. 2020.

PELLEGRINE, E. A dimensão Ética da Competência em Informação: a experiência narrada dos bibliotecários do Instituto Federal de Educação, Ciência e Tecnologia de Santa Catarina (IFSC). 2016. 301 p. Dissertação (Mestre em Ciência da Informação) - Universidade Federal de Santa Catarina, Florianópolis, 2016. Disponível em:

https://repositorio.ufsc.br/xmlui/bitstream/handle/123456789/167928/341346.pdf?sequen ce=1\&isAllowed=y. Acesso em: 26 jul. 2020.

SANTOS, C. A. Competência em Informação na formação básica dos estudantes da Educação Profissional e Tecnológica. 2017. 286 f. Tese (Doutorado em Ciência da Informação) Universidade Estadual Paulista, Marília, 2017. Disponível em:

https://www.marilia.unesp.br/Home/PosGraduacao/CienciadaInformacao/Dissertacoes/santos ca do.pdf. Acesso em: 27 jun. 2020.

SOUSA, M. M. A função educativa do bibliotecário no século XXI: desafios para sua formação e atuação. 2014. 194f. Tese (Doutorado em Ciência da Informação) - Escola de Comunicação e Artes da Universidade de São Paulo, São Paulo, 2014. Disponível em: https://www.teses.usp.br/teses/disponiveis/27/27151/tde-20102014111350/publico/MargaridaMariadeSousaVC.pdf. Acesso em: 27 jun. 2020.

SPUDEIT, D. Proposta de um programa para desenvolvimento de Competência em Informação para alunos do ensino profissional. Ciência da Informação em Revista, Maceió, v. 2, n. 2, p. 67-77, maio/ago. 2015. Disponível em: https://www.seer.ufal.br/index.php/cir/article/view/1782/1466. Acesso em: 27 jun. 2020.

SPUDEIT, D.; VIAPIANA, N.; VITORINO, E. V. Bibliotecário e Educação a Distância (EAD): mediando os instrumentos do conhecimento. Revista ACB, Florianópolis, v. 15, n. 1, p. 54-70, jan. /jun. 2010. Disponível em: https://revista.acbsc.org.br/racb/article/download/695/pdf 18. Acesso em: 27 jun. 2020. 
VEIGA, M. S. Práticas de Letramento Informacional: o uso da informação como caminho da aprendizagem nas bibliotecas multiníveis do Instituto Federal de Rondônia. 2017.126 p. Dissertação (Mestre em Educação Escolar) - Universidade Federal de Rondônia, Porto Velho, 2017. Disponível em:

http://www.mepe.unir.br/uploads/91341742/arquivos/Disserta o Miri CORRIGIDA FINA L mika 145619503.pdf. Acesso em: 27 jun. 2020.

VITORINO, E. V. A perspectiva da Competência Informacional na Educação a Distância (EAD). Informação \& Sociedade: estudos, João Pessoa, v. 19, n. 2, p. 37-44, maio/ago. 2009. Disponível em: https://periodicos.ufpb.br/ojs2/index.php/ies/article/view/1834/3023. Acesso em: 27 jun. 2020.

VITORINO, E. V.; PIANTOLA, D. Competência informacional - bases históricas e conceituais: construindo significados. Ciência da Informação, Brasília, v. 38, n. 3, p. 139-141, set./dez. 2009. Disponível em: http://revista.ibict.br/ciinf/article/view/1236/1414. Acesso em: 27 jun. 2020.

VITORINO, E. V.; PIANTOLA, D. Dimensões da competência informacional (2). Ciência da Informação, Brasília, v. 40, n. 1, p. 99-110, jan./abr. 2011. Disponível em:

http://revista.ibict.br/ciinf/article/view/1328/1507. Acesso em: 27 jun. 2020. 